\title{
Bent Guide Wire of Central Venous Catheter
}

Sir,

A 58-year-old male patient with severe triple vessel coronary artery disease was scheduled for coronary artery bypass grafting surgery. After smooth induction of anesthesia, the proper position was given to insert a central venous catheter (CVC) in internal jugular vein. Location of vein was identified using anatomical landmarks. An eighteen-gauge needle was inserted in the internal jugular vein, and after confirming smooth backflow, guide wire was passed which went smoothly. The needle was removed, and dilator was inserted over the guide wire to create the passage for CVC. The dilator was seen to be little bent as it was removed after dilating the passage. $\mathrm{CVC}$ was rolled over the guide wire. While passing over the catheter over the guidewire, the wire appeared to have sharp bent [Figure 1]. CVC was rolled over the bent of wire with difficulty. After removing guide wire, backflow in all 3 lumens was smooth and nonpulsatile confirming venous placement.

Reported central venous cannulation complications vary according to the anatomic site and operator experience. Complications rate varies from $15 \%$ to $33 \%$ of attempts in some studies. ${ }^{[1,2]}$ Various complications reported are arterial puncture $(5 \%)$, failure to place the catheter $(22 \%)$, catheter malposition $(4 \%)$, pneumothorax $(1 \%)$, hemothorax $(<1 \%)$, subcutaneous hematoma (1\%), and asystolic cardiac arrest $(<1 \%)$. However, bending of the guide wire can create a problem in passing over the CVC. It is essential to follow proper insertion technique. Once the guide wire has been placed, dilator should follow the course of the wire in a parallel way. If the dilator is forced in a more vertical direction, it can easily cause bending of wire and dilator [Figure 2].

\section{Financial support and sponsorship}

Nil.

\section{Conflicts of interest}

There are no conflicts of interest.

Monish S. Raut, Priyanka Gupta ${ }^{1}$, Sandeep Joshi, Arun Maheshwari Department of Cardiac Anesthesiology, Sir Ganga Ram Hospital, New Delhi, 'Department of Cardiac Anesthesia, Amrita Institute of Medical Sciences, Kochi, Kerala, India

Address for correspondence: Dr. Monish S. Raut, Department of Cardiac Anesthesiology, Sir Ganga Ram Hospital, New Delhi, India. E-mail: drmonishraut@gmail.com

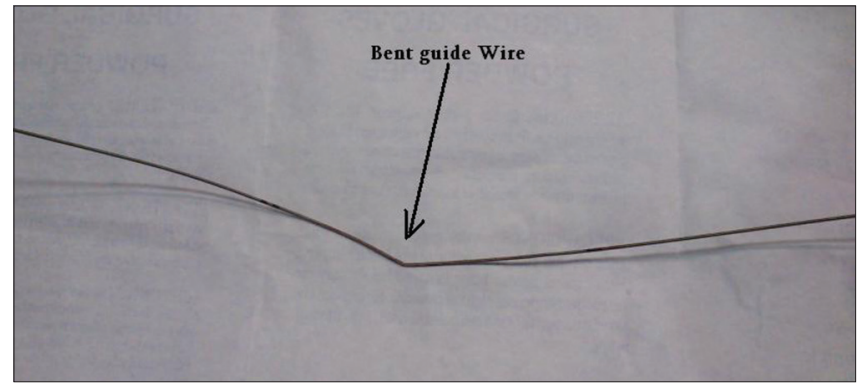

Figure 1: Bent guide wire.

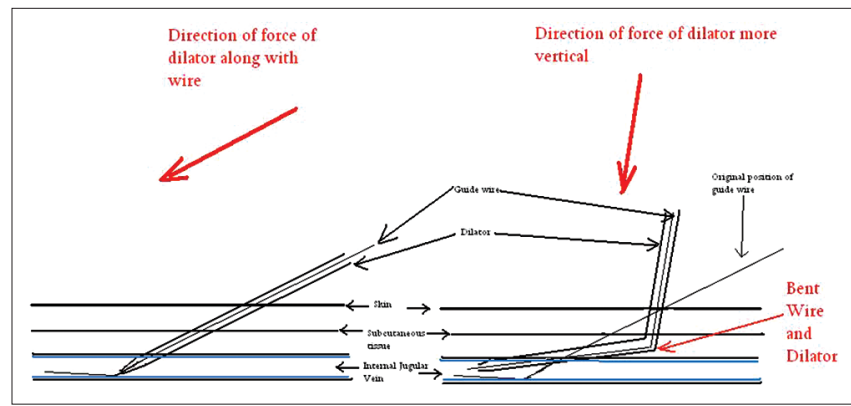

Figure 2: Schematic diagram showing mechanism of bent guide wire.

\section{RefEREnCES}

1. McGee DC, Gould MK. Preventing complications of central venous catheterization. N Engl J Med 2003;348:1123-33.

2. Eisen LA, Narasimhan M, Berger JS, Mayo PH, Rosen MJ, Schneider RF. Mechanical complications of central venous catheters. J Intensive Care Med 2006;21:40-6.

This is an open access article distributed under the terms of the Creative Commons Attribution-NonCommercial-ShareAlike 3.0 License, which allows others to remix, tweak, and build upon the work non-commercially, as long as the author is credited and the new creations are licensed under the identical terms.

\begin{tabular}{|l|l|}
\hline \multicolumn{3}{|c|}{ Access this article online } \\
\hline Quick Response Code: & Website: \\
& www.ijccm.org \\
\hline
\end{tabular}

How to cite this article: Raut MS, Gupta P, Joshi S, Maheshwari A. Bent guide wire of central venous catheter. Indian J Crit Care Med 2017;21:110. 